\title{
Intra-articular corticosteroid injections in osteoarthritis: do they work and if so, how?
}

Intra-articular (IA) corticosteroids are recommended in several guidelines for the treatment of patients with knee osteoarthritis (OA). ${ }^{12}$ They are also widely used: a recent survey of rheumatologists in the United States suggesting that over $95 \%$ use them at least 'sometimes' and 53\% 'frequently'. ${ }^{3}$ Before considering mechanisms of action of IA corticsteroids we should first consider the evidence that they are effective in OA.

A recent systematic review ${ }^{4}$ summarised evidence from five controlled studies of IA corticosteroid in patients with OA knee. Using a quality rating system (originally designed to assess methodology and reporting of NSAID studies), critical analysis showed that none of the studies achieved a score of more than 3 out of a possible 8 for design. It would not be unreasonable, therefore, to conclude that our knowledge of the efficacy of corticosteroid in OA is based on inadequate data. Table 1 summarises the five studies, and two more recent studies. Generally, they show a positive effect but one that is short lived and confounded by a powerful response to placebo (in all cases an equal volume of saline). In one study, ${ }^{5}$ for example, both placebo and corticosteroid groups showed significant decreases in pain at one week, lasting for the duration of the study (eight weeks). A more recent double blind, placebo controlled, crossover study ${ }^{6}$ found a significantly greater decrease in pain with corticosteroid than placebo at three weeks. The inability to detect an effect of corticosteroids beyond three weeks may reflect insensitivity of pain as an outcome measure, rather than a lack of corticosteroid effect.

There is, therefore, some discordance between the modest and short lived benefit over placebo seen in controlled studies and the clinical experience of most rheumatologists that some patients achieve a significant and sustained response. Is it possible to predict those subjects who will respond? One study ${ }^{6}$ examined a range of factors including function, psychosocial and disease related features. None unequivocally predicted response at three weeks (though local tenderness did have some predictive power in unadjusted analysis). Others have reported that presence of effusion, whether detected clinically or by ability to aspirate fluid at time of injection, may predict greater benefit from corticosteroids ${ }^{7}$ but the presence of crystals or raised synovial fluid cell count do not. ${ }^{58}$ The effect of IA corticosteroid may vary from joint to joint but data outside the knee are very limited. Anecdotally, injection at the thumb base may be of prolonged benefit ${ }^{9}$ and is certainly widely recommended though there have been no controlled studies of its efficacy.

If we accept the premise that corticosteroids have a beneficial effect in at least some patients with OA, how may they work? Their speed of onset suggests a direct anti-inflammatory role and certainly this is the action that is most widely recognised. In summary, glucocorticoids act directly on nuclear steroid receptors to control rate of synthesis of mRNA and proteins. This has a number of consequences, including changes in $\mathrm{T}$ and $\mathrm{B}$ cell functions, changes in white cell traffic, alterations in levels of cytokines and enzymes, and inhibition of phospholipase A2 resulting in a reduction in proinflammatory derivatives of arachidonic acid. So is OA an inflammatory disease? Historically, the answer is no: thus OA has been used as a non-inflammatory control for diseases such as rheumatoid arthritis or even as a surrogate for normal tissue. There is, however, accumulating evidence that an inflammatory component may be present in some patients at some phases of the disease. For example, synovial histology may show pronounced synovial hyperplasia and a dense mononuclear cell infiltrate, indistinguishable from that seen in RA. ${ }^{10}$ The inflammation is focal, being most pronounced where synovium is adjacent to cartilage. Recently, expression of oncoproteins ${ }^{11}$ and $\mathrm{NF}-\kappa \mathrm{B},{ }^{12}$ an essential transcription factor for expression of a variety of proinflammatory genes, has also been demonstrated in OA synovium. In vivo, leucocytes can be shown to migrate into OA knee joints. ${ }^{13}$ Finally, systemic markers of inflammation such as $\mathrm{C}$ reactive protein are increased in many patients if a sensitive assay is used and appear to predict progression. ${ }^{14}$ Serum hyaluronic acid, increased in inflammatory arthropathies such as rheumatoid arthritis, is also high in some patients with OA: production of hyaluronic acid by synovial cells in vitro is reduced by corticosteroids. ${ }^{15}$

The cause of inflammation in OA remains unclear: the role of cartilage derived macromolecules and calcium containing crystals is controversial. Once initiated, the release of wear particles may contribute to a cycle of inflammation resulting in further activation of synovium and release of cytokines. ${ }^{16}$ Though inflammation can be an important part of healing and repair, in the context of OA it is generally regarded as detrimental: in animal models, for example, the degree of inflammation correlates with the amount of cartilage loss. ${ }^{17}$ In human OA knee inflammation, as reflected by knee effusion and warmth, is associated with poor clinical and radiographic outcome as is the presence of calcium pyrophosphate crystals. ${ }^{18}$ The mechanism by which inflammation may contribute to cartilage loss is thought to be via production of inflammatory cytokines such as interleukin 1, which, in turn, result in release of degradative enzymes such as collagenases and stromelysin as well as prostaglandins and plasminogen activators. ${ }^{19}$ However, it also plays an important part in the symptoms of OA: most notably by modulating pain perception. ${ }^{20}$ Some products of inflammation such as bradykinin or histamine are capable of directly stimulating primary afferent nociceptive fibres while others

Table 1 Controlled trials of intra-articular corticosteroids in $\mathrm{OA}$ (modified with permission from ref 4). All drugs given by intra-articular injection unless otherwise stated

\begin{tabular}{|c|c|c|c|c|c|c|}
\hline Author & Intervention & $\begin{array}{l}\text { Number } \\
\text { (randomised) }\end{array}$ & $\begin{array}{l}\text { Number } \\
\text { (completing) }\end{array}$ & Design & $\begin{array}{l}\text { Duration } \\
\text { (weeks) }\end{array}$ & Efficacy \\
\hline Cederlof 1966 & prednisolone $25 \mathrm{mg} v$ placebo & 44 & 44 & parallel & 8 & Equal \\
\hline Friedman 1980 & TH $20 \mathrm{mg} v$ placebo & 34 & 34 & parallel & 8 & $\mathrm{TH}>$ placebo at 1 week only \\
\hline Dieppe1980 & TH $20 \mathrm{mg} v$ placebo & $12+16$ & $12+16$ & parallel/cross over & 6 and 2 & $\mathrm{TH}>$ placebo at 2 weeks only \\
\hline Valtonen 1981 & TH $20 \mathrm{mg} v$ beta-methasone $6 \mathrm{mg}$ & 42 & 42 & parallel & 24 & $\mathrm{TH}>$ betamethasone \\
\hline Sambrook 1989 & MP $80 \mathrm{mg} v 80 \mathrm{mg}$ peripatellar & 38 & 32 & parallel & 12 & Equal \\
\hline Gaffney 1995 & TH $20 \mathrm{mg} v$ placebo & 84 & 84 & parallel & 6 & $\mathrm{TH}>$ placebo at week 1 only \\
\hline Jones 1996 & MP $40 \mathrm{mg} v$ placebo & 59 & 47 & cross over & 8 & $\mathrm{MP}>$ placebo at 3 weeks only \\
\hline
\end{tabular}

$\mathrm{TH}=$ triamcinolone hexacetonide; $\mathrm{MP}=$ methylprednisolone. 
(prostaglandins, leukotrienes, and interleukins 1 and 6) may sensitise primary afferent nociceptives to mechanical or other stimuli. Corticosteroids, by inhibiting phospholipase A2, reduce the production of these mediators and hence reduce inflammatory pain.

Despite a reasonable theoretical basis, demonstrating an in vivo anti-inflammatory effect of IA corticosteroid in OA has, to date, been difficult. A reduction in synovial permeability, as measured by clearance of $99 \mathrm{~m}$-Tc labelled albumin, has been reported; the clinical response being proportional to the degree of reduction. ${ }^{21}$ The thermographic index, a measure of warmth and hence inflammation, is reduced one week after corticosteroid injection. ${ }^{8}$ One problem may be definition of subgroups. The 'osteoarthritic disorders' are a heterogeneous group of conditions and it is probable that the role of inflammation (and hence, presumably, response to corticosteroids) varies between groups and at different time points. Moreover, OA may be a phasic condition: damage occurring in short bursts rather than in a linear progression. Bone scan appearances, for example, appear to switch on and off over time with evidence of bone activity preceding radiographic change. ${ }^{22}$ Radiographic findings indicate that many joints in patients with established OA remain stable ${ }^{23}$ and some may even improve, ${ }^{24}$ suggesting that the process responsible for damage to the joint is no longer active. Equally, symptoms of OA do not necessarily remain constant: over a two year period $23 \%$ patients in one study reported an improvement in pain. ${ }^{18}$ Inflammation may play a more important part at times of accelerated joint damage: perhaps corticosteroid given at these times would be particularly beneficial.

Evidence from experimental models of OA suggest that corticosteroids, both intra-articular and systemic, may also have a disease modifying role via an effect on cartilage. In a rabbit partial meniscectomy model, for example, intraarticular triamcinolone hexacetonide given before onset of OA resulted in reduced osteophyte formation, cartilage fibrillation, and chondrocyte cloning. ${ }^{25}$ Similar findings have been reported in a guinea pig model $^{26}$ and in the Pond-Nuki dog model, in which even dogs with established OA showed a beneficial effect. ${ }^{27} \mathrm{~A}$ dose dependent reduction in the cartilage proteolytic enzyme stromelysin was demonstrated, accompanied by a reduction in interleukin $1 \beta$ and the oncogenes c-fos and c-myc, both of which may be important for synthesis of metalloproteinases. ${ }^{27}$ This is presumably the mechanism by which triamcinolone hexacetonide results in the observed reduction in osteophyte size and severity of cartilage lesions. Reduced metalloproteinase synthesis after corticosteroids in human OA cartilage explants has also been reported. ${ }^{28}$ It should be noted that not all animal studies have shown IA corticosteroids to be protective against development of $\mathrm{OA}^{29}$ and some actually suggest an increase in loss of cartilage proteoglycan. ${ }^{30}$ These effects seem to be less relevant for primate cartilage and reports of a Charcot-like accelerated joint destruction after corticosteroid injection in human hip OA may reflect the disease itself rather than the treatment. $^{31}$

How could mechanisms of action be investigated further? Selection of subjects with features of inflammation can be attempted by clinical examination using soft tissue tenderness and joint swelling as surrogate measures of synovitis. However, presence of these features does not predict greater response to NSAIDs over paracetamol ${ }^{32}$ and the reliability of such clinical measures is uncertain. Recently, magnetic resonance imaging has been shown to be an extremely sensitive method of detecting synovial inflammation. In rheumatoid arthritis, IA corticosteroids can be shown to reduce synovial effusion volume and synovial inflammation as measured by rate of enhancement after intravenous contrast (Gd-DTPA), an effect being detectable within one day of injection and lasting for several weeks. ${ }^{33}$ Magnetic resonance imaging is also capable of detecting synovial inflammation in $\mathrm{OA}^{34}$ and thus represents a potentially useful tool. Again, using RA as a model, synovial biopsy specimens have shown that corticosteroids decrease expression of genes that play a part in articular destruction such as TIMP, collagenase, and HLA-DR ${ }^{35}$ : this could also be studied in OA. Finally, biochemical markers may be useful though, to date, results have been generally disappointing. A decrease in serum keratan sulphate after a single IA corticosteroid injection in $\mathrm{OA}$ has been reported ${ }^{36}$ suggesting a possible reduction in catabolism of aggrecan but as corticosteroids may also reduce formation of matrix components ${ }^{30}$ interpretation of these results is complex.

In summary, the mechanism of action of IA corticosteroids in OA is difficult to evaluate, especially when evidence for efficacy is relatively weak. Rheumatologists are likely to continue to use them either when all else fails or when we perceive there to be a moderate inflammatory component to the patient's symptoms: in the future we may be able to refine patient selection using techniques such as magnetic resonance imaging or use of serum or synovial markers of inflammation. We should be cautious about extrapolating a protective effect of IA corticosteroids in animal models to human OA. However, if we were able to predict 'at risk' groups using prospective studies of subjects with early disease, we would at least be able to test the hypothesis that selective anti-inflammatory intervention may reduce progression in OA.

The author wishes to thank Paul Dieppe and Marc Hochberg for comments during manuscript preparation

Division of Rheumatology and Clinical Immunology,

P CREAMER

Department of Medicine, University of Maryland,

10 S Pine Street, Baltimore, Maryland 21201-1192, USA

1 Hochberg MC, Altman RD, Brandt KD, Clark BM, Dieppe PA, Griffin MR Guidelines for the medical management of osteoarthritis. Part II: osteoarthritis of the knee. Arthritis Rheum 1995;38:1541-6.

2 Scott DL. Guidelines for the diagnosis, investigation and management of osteoarthritis of the hip and knee. J Roy Coll Phys London 1993;27:391-6.

3 Hochberg MC, Perlmutter DL, Hudson JI, Altman RD. Preferences in the management of osteoarthritis of the hip and knee: results of a survey of community based rheumatologists in the United States. Arthritis Care Res 1996;9:170-6.

4 Towheed TE, Hochberg MC. A systematic review of randomized, controlled trials of pharmacological therapy in osteoarthritis of the knee. Semin Arthritis Rheum 1997:26:755-70.

5 Friedman DM, Moore ME. The efficacy of intraarticular steroids in osteoarthritis: a double blind study. J Rheumatol 1980;7:850-6.

6 Jones A, Doherty M. Intra-articular corticosteroids are effective in osteoarthritis but there are no clinical predictors of response. Ann Rheum Dis 1996;55:829-32.

7 Gaffney K, Ledingham J, Perry JD. Intra-articular triamcinolone hexacetonide in knee osteoarthritis: factors influencing the clinical response. Ann Rheum Dis 1995;54:379-81.

8 Dieppe P, Sathapatayavongs B, Jones H, Bacon PA, Ring EF. Intra-articular steroids in osteoarthritis. Rheum Rehab 1980;19:212-7.

9 Dieppe PA. Are intra-articular steroid injections useful for the treatment of the osteoarthritis joint? Br J Rheumatol 1991;30:199

10 Haraoui B, Pelletier JP, Cloutier JM, Faure MP, Martel-Pelletier J. Synovial membrane histology and immunopathology in rheumatoid arthritis and membrane histology and immunopathology in
osteoarthritis. Arthritis Rheum 1991; 34:153-63.

11 Roivainen A, Soderstrom KO, Pirila L, Aro H, Kortekangas P, MerilahtiPalo R. Oncoprotein expression in human synovial tissue: an immunohistochemical study of different types of arthritis. Br J Rheumatol 1996;35:933-42

12 Marok R, Winyard PG, Coumbe A, Kus ML, Gaffney K, Blades S. Activation of the transcription factor nuclear factor-kappa $\mathrm{B}$ in human inflamed synovial tissue. Arthritis Rheum 1996;39:583-91.

13 Jones AK, al-Janabi MA, Solanki K, Sobnack R, Greenwood A, Doyle DV. In vivo leukocyte migration in arthritis. Arthritis Rheum 1991;34:270-5.

14 Spector TD, Hart DJ, Nandra D, Doyle DV, Mackillop N, Gallimore JR. Low level increases in serum C-reactive protein are present in early osteoarthritis of the knee and predict progressive disease. Arthritis Rheum 1997;40:723-7.

15 Myers SL. Suppression of hyaluronic acid synthesis in synovial organ cultures by corticosteroid suspensions. Arthritis Rheum 1985;28:1275-82.

16 Evans CH, Mears DC. Release of neutral proteinases from mononuclear Evans $\mathrm{CH}$, Mears DC. Release of neutral proteinases from mononuclear
phagocytes and synovial cells in response to cartilaginous wear particles in vitro. Biochim Biophys Acta 1981;677:287-94. 
17 Pelletier JP, Martel-Pelletier J. Role of synovial membrane inflammation in cartilage collagen matrix breakdown in the Pond Nuki dog model of OA cartilage collagen matrix breakdo
Arthritis Rheum 1985;28:554-61.

18 Ledingham J, Regan M, Jones A, Doherty M. Factors affecting radiographic progression of knee osteoarthritis. Ann Rheum Dis 1995;54:53-8.

19 Belcher C, Fawthrop F, Bunning R, Doherty M. Plasminogen activators and their inhibitors in synovial fluids from normal, osteoarthritis, and rheumatoid arthritis knees. Ann Rheum Dis 1996;55:230-6.

20 Kontinnen YT, Kemppinen P, Segerberg M, Hukkanen M, Rees R, Santavirta $S$. Peripheral and spinal neural mechanisms in arthritis with particular reference to treatment of inflammation and pain. Arthritis Rheum 1994;37:965-82.

21 Eymontt MJ, Gordon GV, Schumacher HR, Hansell JR. The effects on synovial permeability and synovial fluid leukocyte counts in symptomatic
osteoarthritis after intraarticular corticosteroid administration. J Rheumaosteoarthritis after intr.

22 Hutton CW, Higgs ER, Jackson PC, Watt I, Dieppe PA. 99mTc HMDP bone scanning in generalised nodal osteoarthritis. II The four hour bone scan predicts radiographic change. Ann Rheum Dis 1986;45:622-6.

23 Dieppe PA, Cushnaghan J, Shepstone L. The Bristol "OA500" study: progressionof osteoarthrits (OA) over 3 years and the relationship between clinical and radiographic features at the knee joint. Osteoarthritis Cartilage 1997;5:87-97.

24 Massardo L, Watt I, Cushnaghan J, Dieppe P. Osteoarthritis of the knee joint: an eight year prospective study. Ann Rheum Dis 1989;48:893-7.

25 Butler M, Colombo C, Hickman L, O’Byrne E, Steele R, Steinetz B. A new model of osteoarthritis in rabbits. III. Evaluation of anti-osteoarthritic effects of selected drugs administered intraarticularly. Arthritis Rheum effects of selected

26 Williams JM, Brandt $\mathrm{KD}$. Triamcinolone hexacetonide protects against fibrillation and osteophyte formation following chemically induced articular cartilage damage. Arthritis Rheum 1985;28:1267-74.

27 Pelletier JP, DiBattista JA, Raynauld JP, Wilhelm S, Martel-Pelletier J. The in vivo effects of intraarticular corticosteroid injections on cartilage lesions, stromelysin, interleukin-1, and oncogene protein synthesis in experimental osteoarthritis. Lab Invest 1995;72:578-86.

28 Pelletier JP, Martel-Pelletier J, Cloutier JM, Woessner JF Jr. Proteoglycandegrading acid metalloprotease activity in human osteoarthritic cartilage, and the effect of intraarticular steroid injections. Arthritis Rheum 1987;30: 541-8.

29 Myers SL, Brandt KD, O'Connor BL. Low dose prednisone treatment does not reduce the severity of osteoarthritis in dogs after anterior cruciate ligament transection. J Rheumatol 1991;18:1856-62.

30 Mankin HF, Conger KA. The acute effects of IA hydrocortisone on articular cartilage in rabbits. J Bone Joint Surg 1966;48:1383-8.

31 Cooper C, Kirwan JR. Risks of corticosteroid therapy. Clin Rheumatol 1990;4:305-32.

32 Bradley JD, Brandt KD, Katz BP, Kalasinski LA, Ryan SI. Treatment of knee osteoarthritis: relationship of clinical features of joint inflammation to the response to a nonsteroidal anti-inflammatory drug or pure analgesic. J Rheumatol 1992;19:1950-4.

33 Ostergaard M, Stoltenberg M, Henriksen O, Lorenzen I. Quantitative assessment of synovial inflammation by dynamic gadolinium-enhanced magnetic resonance imaging. A study of the effect of intra-articular methmagnetic resonance imaging. A study of the effect of intra-articular methylprednisolone
1996;35:50-9.

34 Fernandez-Madrid F, Karvonen RL, Teitge RA, Miller PR, An T, Negendank WG. Synovial thickening detected by MR imaging in osteoarthritis of the knee confirmed by biopsy as synovitis. Magn Reson Imaging 1995; 13:177-83.

35 Firestein GS, Paine MM, Littman BH. Gene expression (collagenase, tissue inhibitor of metalloproteinases, complement, and HLA-DR) in rheumatoid arthritis and osteoarthritis synovium. Quantitative analysis and effect of intraarticular corticosteroids. Arthritis Rheum 1991;34:1094-105.

36 Campion GV, McCrae F, Schnitzer TJ, Lenz ME, Dieppe PA, Thonar EJ. Levels of keratan sulfate in the serum and synovial fluid of patients with osteoarthritis of the knee. Arthritis Rheum 1991;34:1254-9.

Figure 1 Chronic tuberculous arthritis of the elbow with soft tissue alterations.

Comment (From the text of the chapter)

'The first goal of the treatment is to hold the arm in a good position (elbow flexed at right angle and half-pronated)'

Kirmisson. Malattie degli arti. In: Duplay S, Reclus P, eds. Trattato di chirurgia. Turin: Unione Tipografico Editrice, 1895. 